\title{
LC-MS/MS Method for Determination of Colistin in Human Plasma: Validation and Stability Studies
}

\author{
Nada H. Binhashim1', Syed N. Alvi1 ${ }^{(1)}$, Muhammad M. Hammami1,2* \\ ${ }^{1}$ Clinical Studies and Empirical Ethics Department, King Faisal Specialist Hospital \& Research Center, \\ Riyadh, KSA \\ ${ }^{2}$ Alfaisal University College of Medicine, Riyadh, KSA \\ Email: *muhammad@kfshrc.edu.sa
}

How to cite this paper: Binhashim, N.H., Alvi, S.N. and Hammami, M.M. (2021) LCMS/MS Method for Determination of Colistin in Human Plasma: Validation and Stability Studies. International Journal of Analytical Mass Spectrometry and Chromatography, 9, 1-11.

https://doi.org/10.4236/ijamsc.2021.91001

Received: December 17, 2020

Accepted: February 27, 2021

Published: March 2, 2021

Copyright $\odot 2021$ by author(s) and Scientific Research Publishing Inc. This work is licensed under the Creative Commons Attribution International License (CC BY 4.0).

http://creativecommons.org/licenses/by/4.0/

\begin{abstract}
A simple and reliable high performance liquid chromatography tandem mass spectrometry (LC-MS/MS) assay for the determination of colistin A and colistin B in human plasma was developed and validated. Clarithromycin was used as an internal standard (IS). Plasma extraction was performed using C-18 cartridges and methanol containing $0.1 \%$ formic acid. Analysis was performed using Atlantis $\mathrm{dC} 18(2.1 \times 100 \mathrm{~mm}, 3 \mu \mathrm{m})$ column at room temperature and a mobile phase of $0.2 \%$ formic acid in acetonitrile and water (50:50, v:v), delivered at a flow rate of $0.2 \mathrm{ml} /$ minute. Eluent was detected in the positive ion mode using electrospray ionization at the following transitions of mass to charge $(\mathrm{m} / \mathrm{z})$ : colistin A, $585.6 \rightarrow 101.4$; colistin B, $578.7 \rightarrow$ 101.3; and IS, $748.6 \rightarrow 158.4$. No interference by components of blank plasma or commonly used drugs was observed. The relationship between colistin A colistin $\mathrm{B}$ concentrations and their corresponding peak height ratios to the IS was linear over the range of $0.05-10 \mu \mathrm{g} / \mathrm{ml}$. Inter-day coefficient of variation and bias were, respectively, $\leq 11.5 \%$ and -3.0 to 6.0 for colistin $\mathrm{A}$ and $\leq 9.9$ and -4.7 to 3.0 for colistin B. Mean extraction recovery of colistin A, colistin B, and the IS were $97 \%, 94 \%$, and $97 \%$, respectively. The method was applied to assess the stability of colistin A and colistin B in processed samples $\left(24 \mathrm{hr}\right.$. at room temperature, 48 hours at $\left.-20^{\circ} \mathrm{C}\right)$ and unprocessed samples $\left(24 \mathrm{hr}\right.$. at room temperature, 8 weeks at $-20^{\circ} \mathrm{C}$ ) and after three cycles of freeze and thaw found to be $\geq 87 \%$.
\end{abstract}

\section{Keywords}

Colistin, Clarithromycin, Human Plasma, LC-MS/MS 


\section{Introduction}

Colistin A and colistin B are part of polmyxcin E, together with other polypeptides. Commonly, they constitute more than $85 \%$ of polymyxcin $\mathrm{E}$ by weight. They have similar chemical structure with colistin A having one extra methylene moiety [1]. Colistin is one of the oldest antibiotics but is used as last-line treatment for infections caused by multi-drug-resistant gram-negative bacteria [2] [3]. It is commercially available as colistin methanesulfonate for intravenous administration and as colistin sulfate for oral use. Pharmacokinetic of colistin is very variable and it has narrow therapeutic window [4], necessitating careful drug monitoring.

Several analytical methods are reported for measurement of colistin in various biological matrices, including human plasma and urine [5]-[17]. These include thin layer chromatography [6], isotachophoresis [7], capillary electrophoresis [8], and high performance liquid chromatography with ultraviolet [9] or fluorescence detection after dervatization with 9-fluorenylmethyl chloroformate [10] [11] [12] [13] [14]. Liquid chromatography coupled with tandem mass spectrometry (LC-MS/MS) is becoming more frequently used because of its higher selectivity and sensitivity [15] [16] [17]. Most LCMS/MS assays use polymyxin B1 as internal standard [15] [17]. However, in one report, colistin B level was over estimated using this internal standard [17].

In this paper, we report a simple, precise, and rapid LCMS/MS assay for measurement of colistin A and colistin B in human plasma using clarithromycin as an internal standard in order to produce reliable measurement of both colistin $\mathrm{A}$ and colistin B.

\section{Materials and Methods}

\subsection{Instrument}

Sep-Pak classic C-18 cartridges (Waters Corporation, Milford, MA, USA) was used for analyte extraction from plasma samples. Chromatography was performed on an LCMS/MS system consisting of Water Alliance 2695 separation module (Waters Associates, Inc Milford, MA, USA) for solvent delivery and sample introduction, and a Micromass Quattro micro API bench-top triple quadruple mass spectrometer (Micromass, Manchester, UK) interfaced with a Z-spray ESI source as detector. Analysis was performed using reversed phase Atlantis $\mathrm{dC}_{18}$ column $(2.1 \times 100 \mathrm{~mm}, 3 \mu \mathrm{m})$ protected by guard column Symmetry $\mathrm{C}_{18}(3.9 \times$ $20 \mathrm{~mm}, 5 \mu \mathrm{m}$ ) at room temperature. Mass Lynx software (Ver 4.0) working under Microsoft Window XP professional environment was used to control the instrument, data acquisition, peak integration, peak smoothing, and signal-tonoise ratio measurement.

\subsection{Chemical and Reagents}

Colistin sulfate and clarithromycin pure standards were purchased from SigmaAldrich, MO, USA. Formic acid, methanol, and acetonitrile (HPLC grade) were 
purchased from Fisher Scientific, NJ. USA. Water HPLC grade was prepared by reverse osmosis and further purified by passing through a Milli-Q, Synergy System (Millipore, Bedford, MA, USA). Drug-free human plasma was obtained from the blood bank of King Faisal Specialist Hospital \& Research Centre (KFSHRC) Riyadh, Saudi Arabia.

\subsection{Chromatographic Conditions}

The mobile phase consisted of $0.2 \%$ formic acid in acetonitrile and water (50:50, $\mathrm{v}: \mathrm{v})$. It was degassed before use and delivered at a flow rate of $0.2 \mathrm{ml} /$ minute at ambient temperature with a run time of 4 minutes. The electrospray ionization source was operated in the positive-ion mode at a capillary voltage of $3.5 \mathrm{kV}$ and a cone voltage of $35 \mathrm{~V}$. Nitrogen was used as nebulizing and desolvation gas at a flow rate of 50 and $600 \mathrm{~L} / \mathrm{hr}$, respectively. Argon was used as the collision gas at a pressure of $1.28 \times 10^{-3} \mathrm{mbar}$. The optimum collision energy for colistin and the IS was $25 \mathrm{eV}$. The ion source and the desolvation temperatures were maintained at $120^{\circ} \mathrm{C}$ and $350^{\circ} \mathrm{C}$, respectively. Colistin $\mathrm{A}$, colistin $\mathrm{B}$, and the IS were detected in the positive ion using multiple reactions monitoring mode at the following transitions of mass to charge $(\mathrm{m} / \mathrm{z}): 585.6 \rightarrow 101.4,578.7 \rightarrow 101.3$, and $748.6 \rightarrow$ 158.4 , respectively.

\subsection{Preparation of Standard and Quality Control Samples}

Stock solution of colistin (A and B) and IS $(1.0 \mathrm{mg} / \mathrm{ml})$ were prepared in methanol. They were further diluted with plasma (colistin $\mathrm{A}$ and $\mathrm{B}$ ) and water (IS) to produce working solutions of $10 \mu \mathrm{g} / \mathrm{ml}$ for colistin (A \& B) and $0.1 \mu \mathrm{g} / \mathrm{ml}$ for IS. Ten calibration standards in the range of $0.05-10.0 \mu \mathrm{g} / \mathrm{ml}$ and four quality control (QC) samples $(0.05,0.15,5.0$, and $9.0 \mu \mathrm{g} / \mathrm{ml})$ were prepared in human plasma. Calibration standards and QC samples were vortexed for one minute and $1.0 \mathrm{ml}$ aliquots were transferred into Teflon-lined, screw-capped, borosilicate glass $(13 \times 100 \mathrm{~mm})$ culture tubes and stored at $-20^{\circ} \mathrm{C}$ until used.

\subsection{Sample Preparation}

Aliquots of $1 \mathrm{ml}$ blank plasma, calibration curve, or QC samples were allowed to equilibrate to room temperature. To each tube, $150 \mu \mathrm{l}$ of the IS $0.1 \mu \mathrm{g} / \mathrm{ml}$ solution was added and vortexed for 20 seconds. Before loading samples, Sep-Pak C-18 cartridges were conditioned with $1 \mathrm{ml}$ methanol followed by $2 \mathrm{ml}$ water. Then the sample $(1 \mathrm{ml})$ was loaded followed by $1 \mathrm{ml}$ water. Samples were eluted with $1 \mathrm{ml}$ methanol containing $0.1 \%$ formic acid. The eluates were then evaporated to dryness under a gentle nitrogen stream in a heating block at $45^{\circ} \mathrm{C}$, the residues were reconstituted in $100 \mu \mathrm{l}$ of $0.1 \%$ formic acid in water, transferred into auto-sampler vial, and $10 \mu \mathrm{l}$ were injected into the LC-MS/MS system.

\subsection{Stability Studies}

A total of 40 aliquots of four QC samples $(0.05,0.15$, and $9.0 \mu \mathrm{g} / \mathrm{ml})$ were used 
for stability studies. Five aliquots of each QC sample were extracted and immediately analyzed (baseline), five aliquots were allowed to stand on the bench-top for 24 hours at room temperature before being processed and analyzed (counter stability, 24 hours at room temperature), five aliquots were stored at $-20^{\circ} \mathrm{C}$ for eight weeks before being processed and analyzed (long term freezer storage stability), and five aliquots were processed and stored at room temperature for 24 hours or 48 hours at $-20^{\circ} \mathrm{C}$ before analysis (autosampler stability). Finally, fifteen aliquots of each QC sample were stored at $-20^{\circ} \mathrm{C}$ for 24 hours, they were then left to thaw completely at room temperature unassisted. Five aliquots of each QC sample were extracted and analyzed and the rest returned to $-20^{\circ} \mathrm{C}$ for another 24 hours. The cycle was repeated three times (freeze-thaw stability).

\subsection{Method Validation}

The method was validated according to standard procedures described in the US Food and Drug Administration bioanalytical method validation guidance [18]. The validation parameter included specificity, linearity, accuracy, precision, recovery, and stability.

\section{Results and Discussion}

\subsection{Optimization of LC and MS/MS Conditions}

The product and precursor ions of colistin A, colistin B, and clarithromycin (IS) were determined by infusing a standard mixture $(1.0 \mu \mathrm{g} / \mathrm{ml}$ in methanol $)$ in the mass spectrometer using a syringe pump at a flow rate of $20 \mu \mathrm{l} / \mathrm{ml}$. Mass spectrometry acquisition was performed in multiple reaction monitoring (MRM) with positive ion transition mode set at (precursor $[\mathrm{M}-2 \mathrm{H}]^{2+}$ to product ion) mass to charge $(\mathrm{m} / \mathrm{z}): 585.6 \rightarrow 101.4,578.7 \rightarrow 101.3,748.6 \rightarrow 158.4$, for colistin A, colistin $\mathrm{B}$, and the IS, respectively. The optimum peak height response were obtained by applying capillary voltage of $3.5 \mathrm{KV}$, cone voltage of $35 \mathrm{~V}$, and collision energy of $25 \mathrm{eV}$. The optimal chromatographic condition consisted of $0.2 \%$ formic acid in acetonitrile and water (50:50, v:v), delivered at a flow rate of 0.2 $\mathrm{ml} /$ minute. Analysis was completed within 4 minutes run time. The retention time of colistin A, colistin B and the IS were around 1.4, 1.4, and 2.8 minutes, respectively. Figure 1 represents total ion chromatogram (TIC) of colistin A, colistin B and IS extracted from plasma.

\subsection{Specificity}

We screened six blank plasma samples and seven commonly used drugs including aspirin, acetaminophen, ranitidine, nicotinic acid, caffeine, diclofenac and omeprazole for interferences with colistin A and colistin B, or IS. No drug or endogenous component co-eluted with colistin A, colistin B or the IS. Figure 2(A) depicts a representative chromatogram of drug free human plasma (blank) used in preparation of standards and quality control samples. Figure 2(B) depicts blank plasma spiked with the IS $(0.015 \mu \mathrm{g})$. 


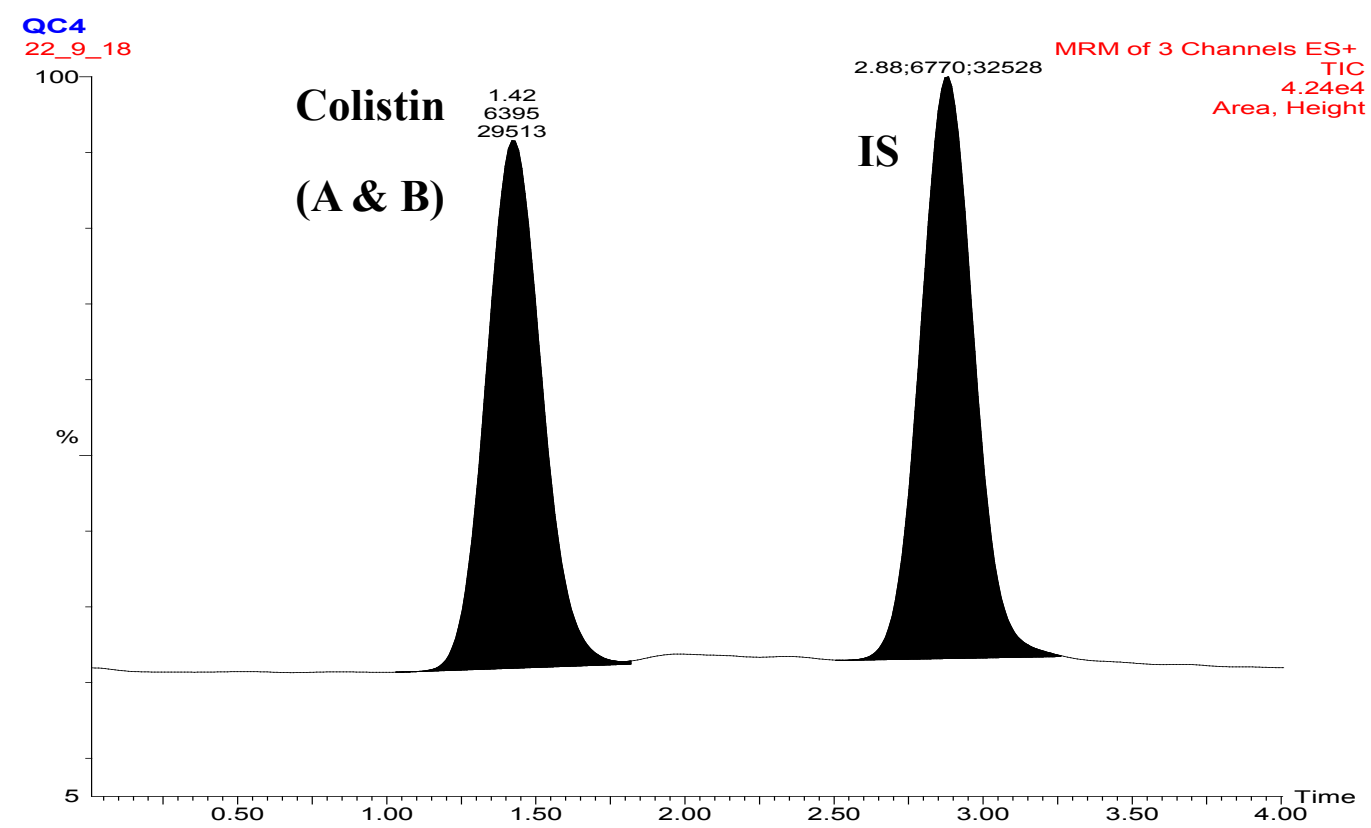

Figure 1. Total ion current chromatogram of standard mixture containing colistin A, colistin B, and clarithromycin (IS) extracted from plasma.

blank

18112019_377

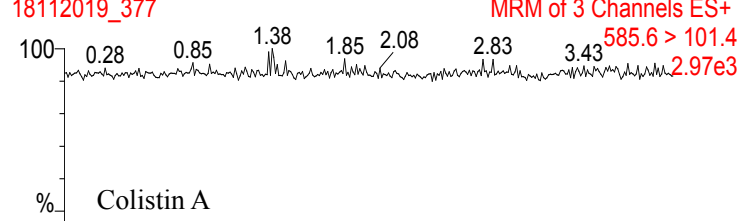

$\%$

Colistin A

5

18112019_377

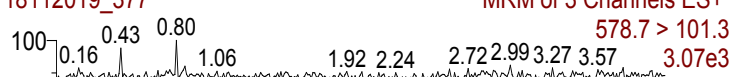

$\%$

Colistin B

5
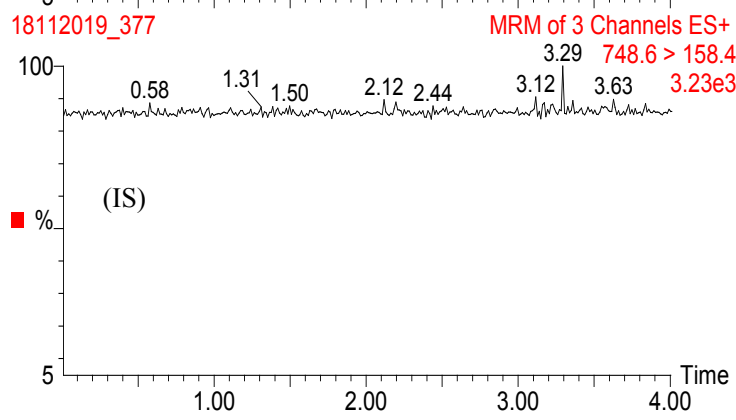

0

B) IS spiked blank plasma

25022020_15

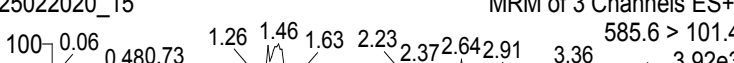
$100 \quad 0.480 .73 \quad 3.267^{2.642 .91} 3.36 \quad 3.92 \mathrm{e} 3$

$\%$

Colistin A

$$
5
$$
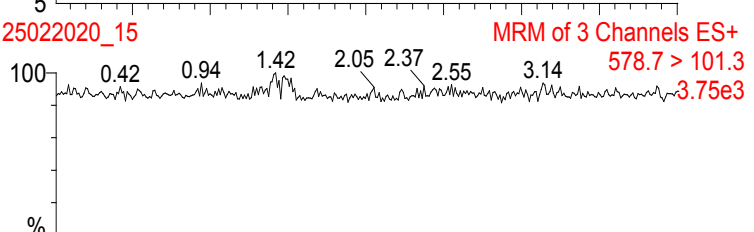

100

Colistin B
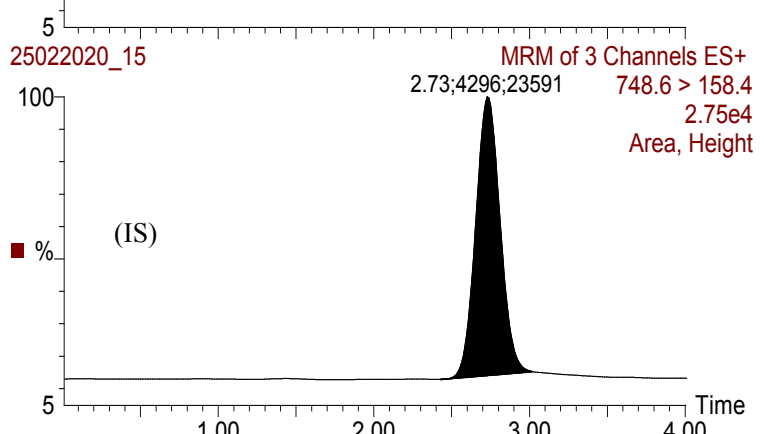

Figure 2. Multiple reaction monitoring chromatogram of blank plasma and blank plasma spiked with IS. 


\subsection{Linearity and Limit of Detection and Quantification}

Linearity of the assay was evaluated by analyzing a series of standard mixtures containing colistin A and colistin B in human plasma at nine concentrations over the range of $0.05-10.0 \mu \mathrm{g} / \mathrm{ml}$. Corresponding peak height ratios to the IS and concentrations were subjected to regression analysis. Mean equations obtained were $y=0.0979 x-0.0029, \mathrm{r}^{2}=0.9901(\mathrm{n}=10)$ and $y=0.0461 x-0.0012$, $r^{2}=0.9921,(n=10)$ for colistin A and colistin B, respectively. The suitability of the calibration curves was confirmed by back calculating the concentration of colistin A and colistin B in human plasma from calibration curves (Table 1). All calculated concentrations were well within the acceptable limits. Figure 3 represents

Table 1. Back-calculated colistin A and colistin B concentrations from ten calibration curves.

\begin{tabular}{|c|c|c|c|c|c|c|}
\hline \multirow{2}{*}{$\begin{array}{c}\text { Nominal } \\
\text { Level } \\
(\mu \mathrm{g} / \mathrm{ml})\end{array}$} & \multicolumn{2}{|c|}{ Colistin A } & \multirow{2}{*}{$\begin{array}{c}{ }^{*} \text { Accuracy } \\
(\%)\end{array}$} & \multirow{2}{*}{$\begin{array}{l}\text { Mean } \\
(\mathrm{SD})\end{array}$} & \multicolumn{2}{|c|}{$\underline{\text { Colistin B }}$} \\
\hline & $\begin{array}{l}\text { Mean } \\
\text { (SD) }\end{array}$ & $\begin{array}{l}{ }^{*} \mathrm{CV} \\
(\%)\end{array}$ & & & $\begin{array}{l}{ }^{*} \mathrm{CV} \\
(\%)\end{array}$ & $\begin{array}{c}* * \text { Accuracy } \\
\text { (\%) }\end{array}$ \\
\hline 0.05 & $0.05(0.01)$ & 8.6 & 107 & $0.05(0.01)$ & 7.8 & 108 \\
\hline 0.1 & $0.10(0.01)$ & 8.4 & 102 & $0.10(0.01)$ & 4.6 & 104 \\
\hline 0.2 & $0.19(0.02)$ & 9.1 & 100 & $0.21(0.02)$ & 8.5 & 105 \\
\hline 0.5 & $0.51(0.06)$ & 11.2 & 100 & $0.51(0.04)$ & 7.7 & 103 \\
\hline 1.0 & $0.98(0.11)$ & 11.4 & 99 & $1.01(0.09)$ & 8.9 & 101 \\
\hline 2.0 & $2.02(0.21)$ & 10.3 & 101 & $2.20(0.12)$ & 6.2 & 101 \\
\hline 4.0 & $4.10(0.28)$ & 6.9 & 102 & $4.01(0.12)$ & 3.1 & 100 \\
\hline 6.0 & $5.90(0.51)$ & 8.6 & 98 & $5.94(0.44)$ & 7.4 & 99 \\
\hline 8.0 & $7.68(0.74)$ & 9.6 & 96 & $7.68(0.61)$ & 8.0 & 96 \\
\hline 10.0 & $10.27(0.44)$ & 4.3 & 103 & $10.27(0.42)$ & 4.0 & 103 \\
\hline
\end{tabular}

${ }^{*}$ Coefficient of variation $(\mathrm{CV})=$ standard deviation $(\mathrm{SD})$ divided by mean measured concentration $\times 100$. ${ }^{* *}$ Accuracy $=$ measured level divided by nominal level $\times 100$.

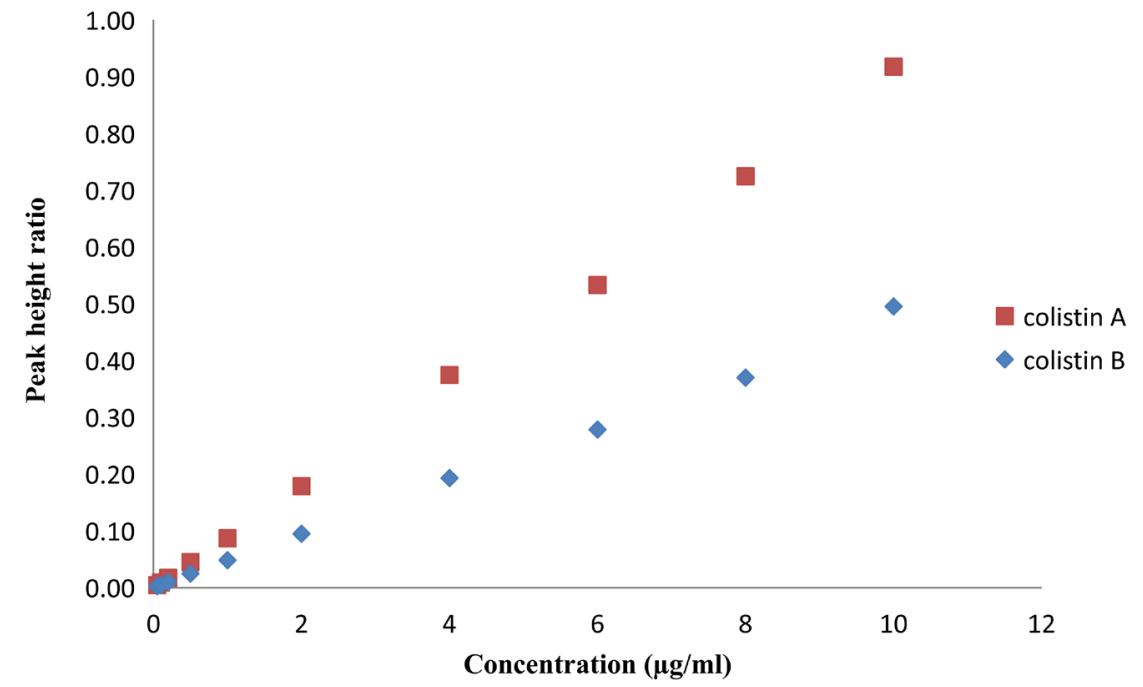

Figure 3. Mean calibration curve for colistin A and colistin B. 
mean calibration curve of colistin A and colistin B. Limit of detection of colistin $A$ and colistin B in plasma were $0.030 \mu \mathrm{g} / \mathrm{ml}$ and $0.035 \mu \mathrm{g} / \mathrm{ml}$, respectively, whereas, limits of quantification were $0.05 \mu \mathrm{g} / \mathrm{ml}$ for both compounds.

\subsection{Precision and Accuracy (Bias)}

Precision and bias were determined for four QC concentrations $(0.05,0.15,5.0$, and $9.0 \mu \mathrm{g} / \mathrm{ml})$. Intra-day precision $(\mathrm{n}=10)$ was $\leq 11.4 \%$ for colistin $\mathrm{A}$ and $\leq 11.2 \%$ for colistin B. Inter-day precision $(n=20$, over three consecutive days) was $\leq 11.5 \%$ for colistin $\mathrm{A}$, and $\leq 9.9 \%$ for colistin $\mathrm{B}$. Inter-day bias was in the range of $-9.1 \%$ to $10.5 \%$ for colistin $A$ and $-8.6 \%$ to $10.2 \%$ for colistin B. Inter-day bias was $-3.0 \%$ to $6.0 \%$ for colistin A, and $-4.7 \%$ to $3.0 \%$ for colistin $\mathrm{B}$. The results are summarized in Table 2. Figure 4 depicts the LC-MS/MS chromatogram of low QC $(0.15 \mu \mathrm{g} / \mathrm{ml})$, and high QC $(9 \mu \mathrm{g} / \mathrm{ml})$ both spiked with IS $(0.015 \mu \mathrm{g})$.

\subsection{Recovery}

Extraction recovery of colistin A and colistin B at four concentrations (0.05, $0.15,5.0$ and $9.0 \mu \mathrm{g} / \mathrm{ml})$ and the IS at one concentration $(0.1 \mu \mathrm{g} / \mathrm{ml})$ were determined by comparing peak heights of spiked-before-extraction samples and spiked-after-extraction samples (5 sets). Mean measured extraction recovery of colistin A, and colistin B was $97 \%$, and $94 \%$, respectively. Recovery of IS was $97 \%$.

\subsection{Matrix Effect}

Matrix effect was quantitatively evaluated by comparing peak heights of colistin

Table 2. Intra- and inter-day precision and bias of colistin A colistin B assay.

\begin{tabular}{|c|c|c|c|c|c|c|}
\hline \multirow{2}{*}{$\begin{array}{c}\text { Nominal } \\
\text { Level } \\
(\mu \mathrm{g} / \mathrm{ml})\end{array}$} & \multicolumn{3}{|c|}{$\begin{array}{l}\text { Measured Level } \\
\text { Colistin A }\end{array}$} & \multicolumn{3}{|c|}{$\begin{array}{c}\text { Measured Level } \\
\text { Colistin B }\end{array}$} \\
\hline & $\begin{array}{c}\text { Mean } \\
(\mathrm{SD})\end{array}$ & $\begin{array}{l}\mathrm{CV} \\
(\%)\end{array}$ & $\begin{array}{l}\text { Bias } \\
(\%)\end{array}$ & $\begin{array}{l}\text { Mean } \\
\text { (SD) }\end{array}$ & $\begin{array}{l}\mathrm{CV} \\
(\%)\end{array}$ & $\begin{array}{l}\text { Bias } \\
(\%)\end{array}$ \\
\hline \multicolumn{7}{|c|}{ Intra-day $(n=10)$} \\
\hline 0.05 & $0.06(0.01)$ & 2.7 & 10.5 & $0.05(0.01)$ & 11.2 & 10.2 \\
\hline 0.15 & $0.14(0.01)$ & 3.1 & -3.6 & $0.15(0.02)$ & 7.6 & 1.2 \\
\hline 5.0 & $4.51(0.28)$ & 6.3 & -9.1 & $4.93(0.25)$ & 5.1 & 0.2 \\
\hline 9.0 & $9.09(1.03)$ & 11.4 & -1.8 & $8.64(0.45)$ & 5.2 & -8.6 \\
\hline \multicolumn{7}{|c|}{ Inter-day $(n=20)$} \\
\hline 0.05 & $0.05(0.01)$ & 11.5 & 6.0 & $0.05(0.01)$ & 9.9 & 3.0 \\
\hline 0.15 & $0.14(0.01)$ & 6.8 & 0.1 & $0.15(0.01)$ & 6.7 & -1.0 \\
\hline 5.0 & $4.87(0.50)$ & 10.3 & -3.0 & $5.09(0.37)$ & 7.3 & -0.3 \\
\hline 9.0 & $9.25(0.82)$ & 8.8 & 3.6 & $8.82(0.64)$ & 7.2 & -4.7 \\
\hline
\end{tabular}

SD, standard deviation. CV, standard deviation divided by mean measured concentration $\times 100$. Bias, measured level - nominal level divided by nominal level $\times 100$. 
$(0.15 \mu \mathrm{g} / \mathrm{ml})$

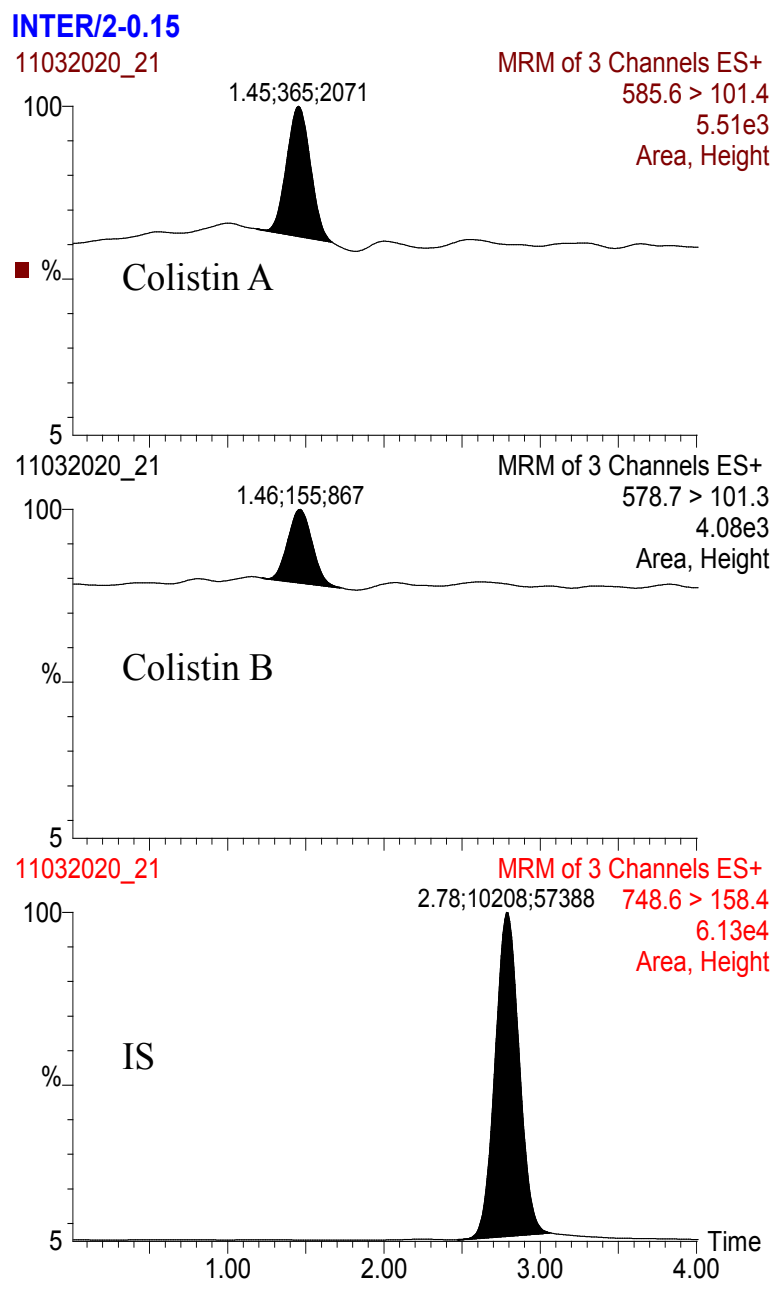

$(9.0 \mu \mathrm{g} / \mathrm{ml})$

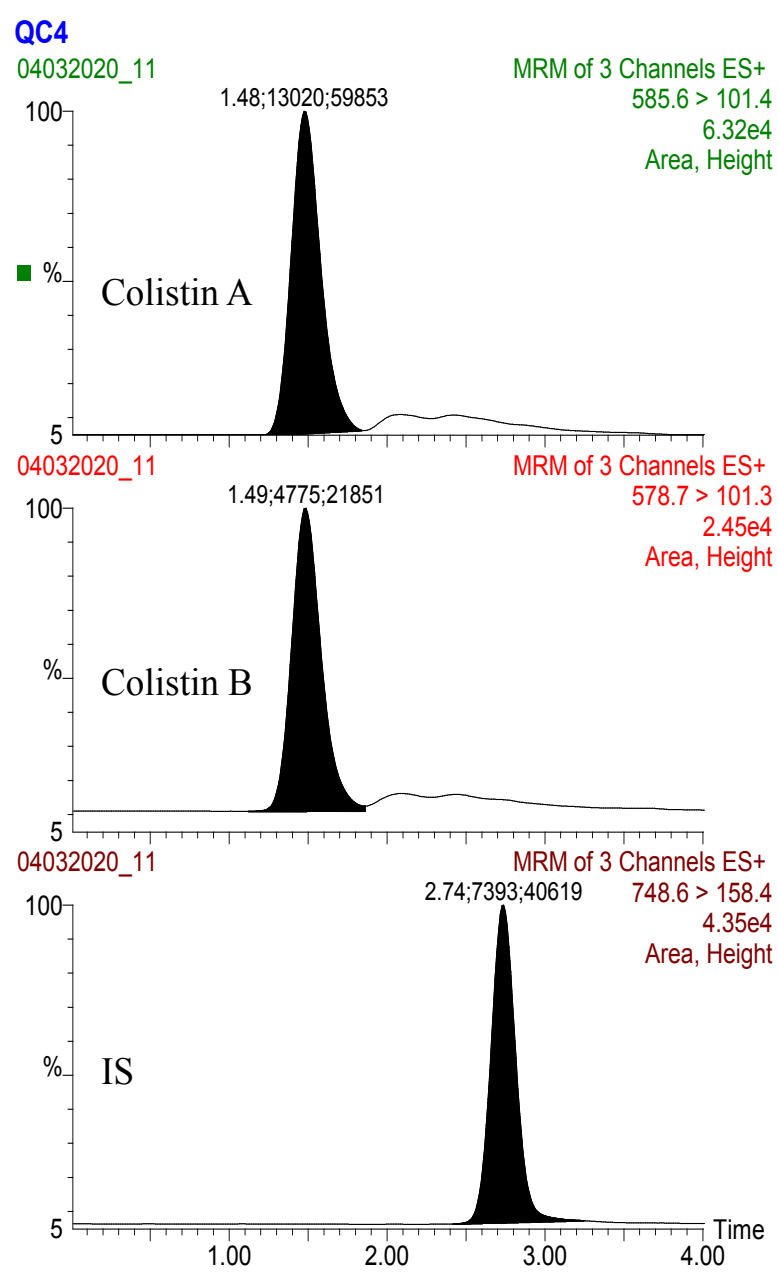

Figure 4. Multiple reaction monitoring chromatogram of two colistin quality control samples in plasma spiked with the IS (0.015 $\mu \mathrm{g})$.

A and colistin B $(0.05,0.15,5$, and $9 \mu \mathrm{g} / \mathrm{ml})$ and the IS $(0.1 \mu \mathrm{g} / \mathrm{ml})$ prepared in human plasma to those prepared in water. Mean ion suppression effect was $-4.9 \%$ for colistin $\mathrm{A},-4.5 \%$ for colistin B and $-1.0 \%$ for the IS.

\subsection{Stability}

Colistin (A and $\mathrm{B}$ ) and the IS stability in processed and unprocessed plasma samples at 3 concentrations $(0.05,0.15$ and $9.0 \mu \mathrm{g} / \mathrm{ml})$ was investigated. Colistin was stable in processed samples for at least 24 hours at room temperature $(\geq 98 \%$ for colistin A and $\geq 92 \%$ for colistin B) and 48 hours at $-20^{\circ} \mathrm{C}$ ( $\geq 105 \%$ for colistin $A$ and $\geq 91 \%$ for colistin B). Colistin in unprocessed plasma samples was stable for at least 24 hours at room temperature ( $\geq 87 \%$ for colistin A and $\geq 92 \%$ for colistin B), at least eight weeks at $-20^{\circ} \mathrm{C}$ ( $\geq 90 \%$ for colistin A $\geq 94 \%$ for colistin B), and after three freeze-and thaw cycles ( $\geq 100 \%$ colistin A and colistin B. Table 3 summaries the results of stability studies. 
Table 3. Stability of colistin A and colistin B under various clinical laboratory conditions.

\begin{tabular}{|c|c|c|c|c|c|c|c|}
\hline \multirow{3}{*}{$\begin{array}{c}\text { Nominal } \\
\text { Level } \\
(\mu \mathrm{g} / \mathrm{ml})\end{array}$} & \multicolumn{2}{|c|}{ Unprocessed } & \multicolumn{2}{|c|}{ Processed } & \multirow{2}{*}{\multicolumn{3}{|c|}{$\begin{array}{c}\text { Freeze-Thaw } \\
\text { Cycle }\end{array}$}} \\
\hline & \multirow{2}{*}{$\begin{array}{c}24 \mathrm{hrs} \\
\text { RT }\end{array}$} & \multirow{2}{*}{$\begin{array}{l}8 \mathrm{wks} \\
-20^{\circ} \mathrm{C}\end{array}$} & \multirow{2}{*}{$\begin{array}{c}24 \mathrm{hrs} \\
\text { RT }\end{array}$} & \multirow{2}{*}{$\begin{array}{l}48 \mathrm{hrs} \\
-20^{\circ} \mathrm{C}\end{array}$} & & & \\
\hline & & & & & 1 & 2 & 3 \\
\hline \multicolumn{8}{|l|}{ Colistin A } \\
\hline 0.05 & 91 & 104 & 99 & 106 & 117 & 118 & 113 \\
\hline 0.15 & 87 & 101 & 98 & 105 & 100 & 103 & 108 \\
\hline 9.0 & 104 & 90 & 106 & 111 & 110 & 109 & 107 \\
\hline \multicolumn{8}{|l|}{ Colistin B } \\
\hline 0.05 & 96 & 107 & 92 & 100 & 114 & 116 & 113 \\
\hline 0.15 & 92 & 95 & 107 & 107 & 107 & 101 & 106 \\
\hline 9.0 & 97 & 94 & 100 & 91 & 110 & 102 & 104 \\
\hline
\end{tabular}

Stability $(\%)=$ mean measured concentration $(\mathrm{n}=5)$ at the indicated time divided by mean measured concentration $(n=5)$ at baseline $\times 100$. Spiked plasma samples were processed and analyzed immediately (baseline, data not shown), after 24 hours at room temperature ( $24 \mathrm{hrs} \mathrm{RT}$ ), after freezing at $-20^{\circ} \mathrm{C}$ for 8 weeks $\left(8 \mathrm{wks},-20^{\circ} \mathrm{C}\right)$, or processed and then analyzed after storing for 24 hours at room temperature (24 hrs, RT) or 48 hours at $-20^{\circ} \mathrm{C}\left(48 \mathrm{hrs},-20^{\circ} \mathrm{C}\right)$.

\section{Conclusion}

The described LCMS/MS assay is simple, precise, and accurate, making it suitable for therapeutic drug monitoring and pharmacokinetic analysis. It requires 1 $\mathrm{ml}$ plasma sample, and the analysis was completed within four minutes. Assay was applied successfully to monitor stability of colistin under various conditions generally encountered in the clinical laboratories.

\section{Conflicts of Interest}

The authors declare no conflicts of interest regarding the publication of this paper.

\section{References}

[1] Ahmed, M.A.E., Zhong, L.L., Shen, C., Yang, Y., Doi, Y. and Tian, G.B. (2020) Colistin and Its Role in the Era of Antibiotic Resistance: An Review (2000-2019). Emerging Microbes \& Infections, 9, 868-885. https://doi.org/10.1080/22221751.2020.1754133

[2] Bergen, P.J., Li, J., Rayner, C.R. and Nation, R.L. (2006) Colistin Methanesulfonate Is an Inactive Prodrug of Colistin against Pseudomonas aeruginosa. Antimicrobial Agents and Chemotherapy, 50, 1953-1958.

https://pubmed.ncbi.nlm.nih.gov/16723551/ https://doi.org/10.1128/AAC.00035-06

[3] Decolin, D., Leroy, P., Nicolas, A. and Archimbault, P. (1997) Hyphenated Liquid Chromatographic Method for the Determination of Colistin Residues in Bovine Tissues. Journal of Chromatographic Science, 35, 557-564. https://pubmed.ncbi.nlm.nih.gov/9397540/ https://doi.org/10.1093/chromsci/35.12.557

[4] Gregoire, N., Climent, V., Magreault, S., Marchand, S. and Couet, W. (2017) Clini- 
cal Pharmacokinetics and Pharmacodynamics of Colistin. Clinical Pharmacokinetics, 56, 1441-1460. https://link.springer.com/article/10.1007/s40262-017-0561-1 https://doi.org/10.1007/s40262-017-0561-1

[5] Zheng, M., Wang, J., Gerber, J. and Milne, R. (2008) Determination of Colistin in Human Plasma, Urine and Other Biological Samples Using LC-MS/MS. Journal of Chromatography B, 862, 205-212.

https://www.sciencedirect.com/science/article/abs/pii/S1570023207008586 https://doi.org/10.1016/j.jchromb.2007.12.009

[6] Thomas, A.H. and Holloway, I. (1978) Thin-Layer Chromatographic Method for the Identification of the Polymyxins. Journal of Chromatography A, 161, 417-420. https://doi.org/10.1016/S0021-9673(01)85266-3

[7] Holska, W. and Gwozdz, E. (1989) Determination of Colistin by Isotachophoresis. Journal of Liquid Chromatography, 12, 2761-2767.

[8] Kristensen, H.K. and Hansen, S.H. (1993) Separation of Polymyxins by Micellar Electrokinetic Capillary Chromatography. Journal of Chromatography A, 628, 309-315. https://www.sciencedirect.com/science/article/abs/pii/002196739380013X https://doi.org/10.1016/0021-9673(93)80013-X

[9] Orwa, J.A., Van Gerven, A., Roets, E. and Hoogmartens, J. (2000) Development and Validation of a Liquid Chromatography Method for Analysis of Colistin Sulphate. Chromatographia, 51, 433-436.

https://link.springer.com/article/10.1007/BF02490480 https://doi.org/10.1007/BF02490480

[10] Li, J., Milne, R.W., Nation, R.L., Turnidge, J.T., Coulthard, K. and Johnson, D.W. (2001) A Simple Method for the Assay of Colistin in Human Plasma, Using PreColumn Derivatization with 9-Fluorenylmethyl Chloroformate in Solid-Phase Extraction Cartridges and Reversed-Phase High-Performance Liquid Chromatography. Journal of Chromatography B: Biomedical Sciences and Applications, 761, 167-175. https://pubmed.ncbi.nlm.nih.gov/11587346/ https://doi.org/10.1016/S0378-4347(01)00326-7

[11] Chepyala, D., Tsai, I.L., Sun, H.Y., Lin, S.W. and Kuo, C.H. (2015) Development and Validation of a High-Performance Liquid Chromatography-Fluorescence Detection Method for the Accurate Quantification of Colistin in Human Plasma. Journal of Chromatography B: Analytical Technologies in the Biomedical and Life Sciences, 980, 48-54. https://europepmc.org/article/med/25589254 https://doi.org/10.1016/j.jchromb.2014.12.015

[12] Hanai, Y., Matsuo, K., Kosugi, T., Kusano, A., Ohashi, H., Kimura, I., Hirayama, S., Nanjo, Y., Ishii, Y., Sato, T., Miyazaki, T., Nishizawa, K. and Yoshio, T. (2018) Rapid, Simple, and Clinically Applicable High-Performance Liquid Chromatography Method for Clinical Determination of Plasma Colistin Concentrations. Journal of Pharmaceutical Health Care and Sciences, 4, Article No. 22.

https://link.springer.com/article/10.1186/s40780-018-0119-x https://doi.org/10.1186/s40780-018-0119-x

[13] Pinho, A.R., Rocha, M., Alves, G., Falcao, A.C. and Fortuna, A.C. (2018) Development and Validation of an HPLC-FLD Technique for Colistin Quantification and Its Plasma Monitoring in Hospitalized Patients. Analytical Methods, 10, 389-396. https://pubs.rsc.org/en/content/articlelanding/2018/ay/c7ay02585h\#!divAbstract https://doi.org/10.1039/C7AY02585H

[14] Gobin, P., Lemaitre, F., Marchand, S., Couet, W. and Olivier, J. (2010) Assay of Colistin and Colistin Methanesulfonate in Plasma and Urine by Liquid Chromatography-Tandem Mass Spectrometry. Antimicrobial Agents and Chemotherapy, 54, 1741 - 
1748. https://pubmed.ncbi.nlm.nih.gov/20176909/ https://doi.org/10.1128/AAC.01367-09

[15] Dorsikas, Y., Markopoulou, C., Koundourellis, J. and Loukas, Y. (2010) Validation of a Novel LC-MS/MS Methods for the Quantification of Colistin A and B in $\mathrm{Hu}$ man Plasma. Journal of Separation Science, 34, 37-45.

https://pubmed.ncbi.nlm.nih.gov/21171174/ https://doi.org/10.1002/jssc.201000680

[16] Bihan, K., Lu, Q., Enjalbert, M., Apparuit, M., Langeron, O., Rouby, J., Brentano, C. and Zahr, N. (2016) Determination of Colistin and Colistimethate Levels in $\mathrm{Hu}$ manplasma and Urine by High Performance Liquid Chromatography-Tandem Mass Spectrometry. Therapeutic Drug Monitoring, 38, 796-803.

https://pubmed.ncbi.nlm.nih.gov/27684296/ https://doi.org/10.1097/FTD.0000000000000345

[17] Leporati, M., Bua, R., Matiano, F., Carignano, P., Stella, M., Biancone, L. and Vincent, M. (2014) Determination by LC-MS/MS of Colistin A and B in Plasma and Ultrafiltrate from Critically Ill Patients Undergoing Continuous Venovenous Hemodiafiltration. Therapeutic Drug Monitoring, 36, 182-191.

https://pubmed.ncbi.nlm.nih.gov/24216535/ https://doi.org/10.1097/FTD.0b013e3182a8997c

[18] Food and Drug Administration, Centre for Drug Evaluation and Research (CDER) (2018) Bioanalytical Method Validation: Guidance for Industry.

https://www.fda.gov/files/drugs/published/Bioanalytical-Method-Validation-Guida nce-for-Industry.pdf 